\title{
Correction to: Impact of agri-fresh food supply chain quality practices on organizational sustainability
}

\author{
Man Mohan Siddh ${ }^{1}$. Sameer Kumar ${ }^{2} \cdot$ Gunjan Soni $^{3} \cdot$ Vipul Jain $^{4} \cdot$ Charu Chandra ${ }^{5} \cdot$ Rakesh Jain $^{3}$. \\ Milind Kumar Sharma ${ }^{6} \cdot$ Yigit Kazancoglu $^{7}$
}

Published online: 19 October 2021

๑) Springer Science+Business Media, LLC, part of Springer Nature 2021

\section{Correction to: Operations Management Research https://doi.org/10.1007/s12063-021-00196-x}

In this article the author name Man Mohan Siddh was incorrectly written as Manmohan Siddh.

In this article several affiliations were incorrect: the affiliation details for Man Mohan Siddh were incorrectly given as 'Jaupur' but should have been 'Jaipur'; the affiliation for Milind Kumar Sharma should have been Department of Production \& Industrial Engineering, M.B.M. Engineering College, Faculty of Engineering \& Architecture, Jai Narain Vyas University, Jodhpur, Rajasthan, India.

The original article has been corrected.

Publisher's Note Springer Nature remains neutral with regard to jurisdictional claims in published maps and institutional affiliations.

The original article can be found online at https://doi.org/10.1007/ s12063-021-00196-x.

\author{
Sameer Kumar \\ skumar@stthomas.edu \\ Man Mohan Siddh \\ manmohansiddh@gmail.com \\ Gunjan Soni \\ gsoni.mech@mnit.ac.in \\ Vipul Jain \\ Vipul.Jain@vuw.ac.nz \\ Charu Chandra \\ charu@umich.edu \\ Rakesh Jain \\ rjain.mnit@gmail.com \\ Milind Kumar Sharma \\ milindksharma@ rediffmail.com \\ Yigit Kazancoglu \\ yigit.kazancoglu@yasar.edu.tr
}

1 Department of Mechanical Engineering, Jaipur Engineering College and Research Centre, Jaipur, India

2 Department of Operations and Supply Chain Management, Opus College of Business, University of St, Thomas Minneapolis Minnesota, Minneapolis, USA

3 Department of Mechanical Engineering, Malaviya National Institute of Technology Jaipur, Jaipur, India

4 School of Management, Victoria Business School, Victoria University of Wellington 23, Lambton Quay, Pipitea Campus, PO Box 600, Wellington 6140, New Zealand

5 Department of Management Studies College of Business, University of Michigan, Michigan, Dearborn, USA

6 Department of Production \& Industrial Engineering, M.B.M. Engineering College, Faculty of Engineering \& Architecture, Jai Narain Vyas University, Jodhpur, Rajasthan, India

7 Dept. of Logistics Management, Yasar University, Universite Cad. No, 37-39, Izmir, Bornova, Turkey 